\title{
Feature-negative effect in serial learning
}

\author{
STEVEN J. HAGGBLOOM and FRANK K. SHEPPARD \\ Arkansas State University, State University, Arkansas
}

\begin{abstract}
Three groups of 6 rats each were trained for 10 days in a straight runway on a reinforcement schedule that provided $14,7,3,1$, and 0.045 -g food pellets over five successive runs each day. For Group FN, the first four food quantities (elements) of the series were unsignaled and the terminal 0-pellet element was signaled by flashing lights suspended over the runway, a featurenegative discrimination problem. For Group FP, the first four elements were signaled by flashing lights and the 0-pellet element was unsignaled, a feature-positive discrimination. Group C experienced the flashing lights as a signal for Elements 1-4 or for Element 5, on alternate days. Under the limited training conditions used here, only Groups FN and FP learned to anticipate, and run slowly to, the 0-pellet element, and that behavior developed faster and was more pronounced in Group FN than in Group FP. Implications of the results for analyses of feature discrimination learning are discussed.
\end{abstract}

Jenkins and Sainsbury (1969) described a discrimination problem, called feature discrimination learning, in which the discriminative cue was the presence versus the absence of a distinctive stimulus (feature). In the featurepositive (FP) case, the presence of the feature was the positive ( $\mathrm{S}+$ ) cue and signaled reinforcement, and its $\mathrm{ab}-$ sence was the negative $(\mathrm{S}-$ ) cue and signaled nonreinforcement. In the feature-negative (FN) case, the feature's presence was $S-$ and its absence was $S+$. The vast majority of feature learning experiments, including those reported initially by Jenkins and Sainsbury (1969), have found faster learning of FP discriminations than FN discriminations, a finding called the feature-positive effect (FPE).

Based on results of an experiment employing rats trained on a go/no-go discrimination problem in the runway, Haggbloom (1983) reported faster learning of an FN discrimination than of an FP discrimination, a featurenegative effect (FNE). Except for the use of a runway, all other aspects of the procedures used by Haggbloom (1983) were present either alone or in some combination in previous experiments reporting FPEs.

Haggbloom (1983) suggested that the FPE may occur in situations where a signal to respond is more valuable than one not to respond, and the FNE may occur where a signal not to respond is more valuable than one to respond. The identifying characteristics of the two kinds of situations remain to be determined. However, in the course of experiments on serial learning in rats, it occurred to us that the serial learning task was one in which correct responding would likely be facilitated more by a signal not to respond, an FN problem, than by a signal to respond, an FP problem. The present experiment investigated that possibility.

The serial learning task employed here was originally

This experiment was supported by a Faculty Research Grant from Arkansas State University to the first author. Requests for reprints should be addressed to S. J. Haggbloom, Department of Psychology, Arkansas State University, P.O. Box 2127, State University, AR 72467. described by Hulse and Dorsky (1977). Rats received a decreasing number of $.045-\mathrm{g}$ food pellets over five successive runs, getting 14 pellets on the first run, then 7 , 3,1 , and, finally, 0 pellets. Rats trained on this series learn to anticipate, and run slowly to, the terminal nonreinforcement or 0-pellet element.

There were three groups in the present experiment, each of which received a single daily presentation of the series 14-7-3-1-0. The groups differed with respect to whether the feature signaled reinforcement on Runs 1-4 (Group FP), nonreinforcement on Run 5 (Group FN), or, in the case of the control group (Group C), reinforcement on odd-numbered days and nonreinforcement on evennumbered days. The feature was a series of flashing lights over the runway. We predicted faster serial learning in Group FN than in Group FP, a feature-negative effect.

\section{METHOD}

\section{Subjects}

The subjects were 18 male rats, bred in the laboratory from Holtzman stock, 75 days old at the beginning of training.

\section{Apparatus}

The apparatus consisted of a straight black runway, $130 \mathrm{~cm}$ long $X$ $9 \mathrm{~cm}$ wide. The first $25 \mathrm{~cm}$ made up the startbox and the last $25 \mathrm{~cm}$ constituted the goalbox. The startbox was separated from the runway by a manually operated guillotine door. The goalbox, separated from the runway in the same manner, contained an unpainted wooden goal cup. Running times were recorded from the opening of the startbox door, which triggered a .01 -sec clock, to the location of a photocell $5 \mathrm{~cm}$ from the distal end of the goalbox.

A seris of six 24-V dc lights was suspended $2 \mathrm{~cm}$ above the hardwarecloth lid of the runway. The lights were located at $24.5-\mathrm{cm}$ intervals, beginning $2 \mathrm{~cm}$ past the startbox door and terminating directly over the goal cup $2 \mathrm{~cm}$ from the end wall of the goalbox. The lights were controlled by an interval timer activated by the opening of the startbox door (on feature trials) and set so that the lights would flash repeatedly for $.5 \mathrm{sec}$ on $/ .5 \mathrm{sec}$ off.

\section{Procedure}

The rats were housed individually throughout the experiment. All food was removed from each rat's cage 14 days prior to the start of experimental training. Thereafter, each rat received $12 \mathrm{~g}$ of lab chow per day mi- 
nus the amount of food received in the runway. Water was always available in the home cage and between trials. On Days 12-14 of deprivation, the rats were handled in squads of 3 for $3 \mathrm{~min}$ per squad and subsequently fed $14.045-\mathrm{g}$ Noyes food pellets from a small dish placed in the home cage. Six rats were randomly assigned to each of three groups, and training began on Day 15 of deprivation.

Each rat received five successive runs terminating in 14, 7, 3, 1, and 0 food pellets on each of 12 days of training. For Group FP, Runs 1-4 (to pellet quantities 14, 7, 3, and 1) were always signaled by presentation of the feature (flashing light), and the terminal 0-pellet or nonreinforced Run 5 was always unsignaled. For Group FN, reinforced Runs 1-4 were always unsignaled, and nonreinforcement on Run 5 was always signaled by the presentation of the feature. For Group $C$, the feature occurred on Runs 1-4 on odd-numbered days of training, and Run 5 was unsignaled. On even-numbered days, the feature occurred on Run 5, and Runs 1-4 were unsignaled.

The subjects were administered their daily trials in squads consisting of 1 rat from each group. The order in which subjects were run within squads was randomized daily, and the order of successive squads was held constant across days. Within a squad, the first subject was administered all five runs of the series, separated by a 10-15 sec interval, before the next subject was run.

To initiate a run, the startbox door was opened approximately $3 \mathrm{sec}$ after the rat was placed in the startbox, regardless of the rat's orientation. The rat was allowed a maximum time of $60 \mathrm{sec}$ to complete the run, after which the rat was placed in the goalbox. Subjects were removed from the goalbox immediately after the reinforcement was consumed, or after $20 \mathrm{sec}$ in the case of nonreinforcement.

\section{RESULTS}

Figure 1 shows the mean running time for each of the three groups to all five pattern elements over the last 4 days of training. Note that all three groups ran slower to the terminal 0-pellet element than to earlier elements in the series, but anticipation of 0 pellets was best in Group FN, worst in Group C, and intermediate in Group FP.

A groups $\times$ runs $\times$ days analysis of variance (ANOVA) applied to the data shown in Figure 1 yielded a reliable groups $\times$ runs interaction $[F(8,60)=3.39$, $p<.01]$. Subsequent planned comparisons among group

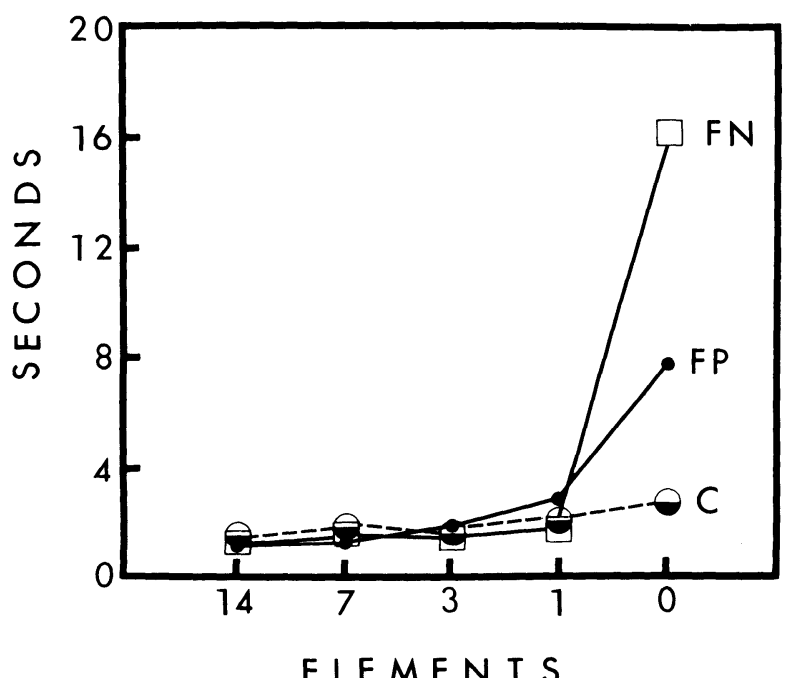

Figure 1. Mean group running time for each group to all five pattern elements collapsed over the last 4 days of training. mean running times on Run 5 showed that Group FN ran reliably slower than Groups FP $[F(1,15)=12.42$, $p<.01]$ and $C[F(1,15)=30.95, p<.01]$, but that Group FP did not run slower than Group $C[F(1,15)=$ $4.15, p>.05]$. Comparisons between each group's running time on Run 1 versus Run 5 showed that times were reliably slower on Run 5 than on Run 1 in Group FN $[F(1,60)=30.92, p<.01]$ and in Group FP $[F(1,60)$ $=12.42, p<.01]$, but not in Group $\mathrm{C}(F<1)$. Group $C$ did not show any tendency toward slower running on Run 5 when that run was signaled than when it was unsignaled.

\section{DISCUSSION}

The present results are consistent with the prediction that serial learning occurs faster in a feature-negative condition, in which the presence of the feature signals the 0 -pellet element, than in a feature-positive condition, in which the 0 -pellet element is signaled by the absence of the feature (a feature-negative effect). This experiment employed very limited training on the 14-7-3-1-0 series. Consequently, slow running to 0 pellets did not develop in Group $\mathrm{C}$ by the end of training. Compared to Group $\mathrm{C}$, in which the feature was irrelevant, feature-positive training also facilitated serial learning.

Rats trained on the 14-7-3-1-0 series employed here generally run relatively fast, and at about the same speed, to the first four elements of the series, and markedly slower to the terminal 0-pellet element (e.g., Haggbloom \& Brooks, 1985; Haggbloom \& Ekdahl, 1985; Hulse \& Dorsky, 1977). That pattern of behavior occurred here in Groups FN and FP, being more pronounced in Group FN. For the rat, then, the predominant characteristic of the task would appear to be learning to discriminate the occurrence of the 0 -pellet element from the remaining elements. This discrimination is evidently easier to learn if the location of the 0-pellet element is signaled by a distinctive cue, as in Group FN, than if its location is signaled by the absence of that same cue, as in Group FP.

Hearst (1984) suggested that people and animals have an information processing bias favoring the presence over the absence of a stimulus as a source of information, and that the FPE is a consequence of that bias. Haggbloom (1983), however, argued that although the presence of a stimulus may generally be more informtive than its absence, the FPE was not a necessary consequence of that bias. Instead, a task on which a signal not to respond is more valuable than one to respond should produce an FNE. The task of locating, and running slowly to, the 0 pellet element of the 14-7-3-1-0 series appears to be such a task.

\section{REFERENCES}

HAGGBLoOM, S. J. (1983). Feature-negative effect in rats' discrimination learning in the runway. Animal Learning \& Behavior, 11, 367-372. HAGGBloOM, S. J., \& BrooKS, D. M. (1985). Serial anticipation and pattern extrapolation in rats as a function of element discriminability. Animal Learning \& Behavior, 13, 303-308.

HaGgBloOM, S. J., \& EKDAHL, M. W. (1985). Effects of interrun interval on serial learning. Animal Learning \& Behavior, 13, 98-102.

HEARST, E. (1984). Absence as information: Some implications for learning, performance, and representational processes. In H. L. Roitblat, T. G. Bever, \& H. S. Terrace (Eds.), Animal cognition (pp. 311-332). Hillsdale, NJ: Erlbaum.

HulSE, S. H., \& DORSKY, N. P. (1977). Structural complexity as a determinant of serial pattern learning. Learning \& Motivation, 8, 488-506.

JenkINS, H. M., \& SAINSBURY, R. S. (1969). The development of stimulus control through differential reinforcement. In N. J. Mackintosh \& W. K. Honig (Eds.), Fundamental issues in associative leaming (pp. 123-161). Halifax: Dalhousie University Press.

(Manuscript received for publication February 18, 1986.) 